\title{
Percepção ambiental: um estudo numa escola pública municipal de Chapecó - Santa Catarina
}

\author{
Unidade Central de Educação Faem Faculdades \\ Ivo Dickmann \\ Ireno Antonio Berticelli \\ Universidade Comunitária da Região de Chapecó
}

\section{Resumo}

Este artigo analisa as percepções que emergem do imaginário de estudantes numa Escola Municipal de Ensino Fundamental de Chapecó-Santa Catarina. Teve, como referência, a teoria da complexidade de Morin, a pedagogia libertadora de Freire e a fenomenologia de Merleau-Ponty. O estudo foi realizado em duas turmas do $9^{\circ}$ ano, e a abordagem foi por meio de desenhos, selecionados com base nas categorias: relação ser humano e mundo; ser humano e natureza; ser humano e sociedade e educação e auto-organização. Os resultados demonstram diferenças de percepçães entre as duas turmas. Enquanto uma apresenta uma percepção mais complexa entre as relações, a outra turma pouco consegue perceber as ligações existentes que, referente à relação ser humano e meio ambiente, contribui para uma problematização no âmbito social, político e educacional. Pretende-se que este estudo fomente discussões em outros níveis educacionais em prol da mudança paradigmática, superando, assim, a fragmentação do pensamento e do conhecimento socioambientais. Palavras-chave: Percepção. Ensino fundamental. Educação ambiental. Desenho.

\section{Environmental perception: a study in a municipal public school of Chapecó - Santa Catarina}

\begin{abstract}
This article analyzes the perceptions that emerge from the imaginary of students in a Municipal Elementary School of Chapecó-SC. It had as reference the theory of the complexity of Morin, the liberating pedagogy of Freire and the phenomenology of Merleau-Ponty. The study was carried out in two groups of the 9th year and the approach was through drawings, selected from the categories: human being and world relation; human being and nature; human being and society and education and self-organization. The results demonstrate differences in perceptions between the two classes. While one presents a more complex perception between relationships, the other group can not perceive the existing connections that, referring to the relation between human being and environment, contributes to a problematization in the social, political and educational scope. It is intended that this study foster discussions at other educational levels in favor of paradigmatic change, thus overcoming the fragmentation of socio-environmental thinking and knowledge.

Keywords:Perception. Elementary school. Environmental education. Drawing.
\end{abstract}


Percepção ambiental: um estudo numa escola pública municipal de Chapecó - Santa Catarina

\section{Percepción ambiental: un estudio en una escuela pública municipal de Chapecó - Santa Catarina}

\section{Resumen}

Este artículo analiza las percepciones que emergen del imaginario de estudiantes en una Escuela Municipal de Enseñanza Fundamental de Chapecó- Santa Catarina. Se tuvo como referencia la teoría de la complejidad de Morin, la pedagogía liberadora de Freire y la fenomenología de Merleau-Ponty. El estudio fue realizado en dos grupos del $9^{\circ}$ año y el abordaje fue a través de dibujos, seleccionados a partir de las categorías: relación ser humano y mundo; ser humano y naturaleza; ser humano y sociedad y educación y autoorganización. Los resultados demuestran diferencias de percepciones entre las dos clases. Mientras una presenta una percepción más compleja entre las relaciones, la otra clase apenas logra percibir los vínculos existentes que, referente a la relación ser humano y medio ambiente, contribuye a una problematización en el ámbito social, político y educativo. Se pretende que este estudio fomente discusiones en otros niveles educativos en pro del cambio paradigmático, superando así la fragmentación del pensamiento y del conocimiento socioambientales. Palabras clave: Percepción. Enseñanza fundamental. Educación ambiental. Dibujo.

\section{Introdução}

Considerando a complexidade da qual emerge e permeia o estudo da educação ambiental, se faz necessário reconhecer a importância das dimensões objetivas e subjetivas dos indivíduos; da forma como eles percebem, representam e se relacionam com o meio ambiente. Assim, urge que a percepção ambiental possa ser vista como um dos meios para a compreensão do mundo, das relações estabelecidas, mas, principalmente, da educação. Desta forma, são pertinentes as palavras de Merleau-Ponty para dizer que:

Tudo aquilo que sei do mundo, mesmo por ciência, eu o sei a partir de uma visão minha ou de uma experiência do mundo sem a qual os símbolos da ciência não poderiam dizer nada [...]. Retornar às coisas mesmas é retornar a este mundo anterior ao conhecimento do qual o conhecimento sempre fala (MERLEAU-PONTY, 1999, p. 3).

Tomando como ponto de partida a relação estabelecida entre o ser humano e o mundo, do ser humano com a natureza, foi o que fez Edgar Morin (2003) quando sugeriu que, desde a Educação Infantil, os debates e as problematizações acerca das questões socioambientais fossem percebidos em sua 
complexidade, não ignorando a experiência do sujeito. É um saber que não se separa do indivíduo, com quem se encarna.

Desta forma, este artigo apresenta os resultados obtidos na pesquisa de mestrado que teve, como objetivo, analisar, por meio de desenhos, qual a percepção de meio ambiente dos estudantes do $9^{\circ}$ ano do ensino fundamental, de uma escola situada no município de Chapecó-Santa Catarina.

\section{Metodologia}

Para desenvolver a pesquisa, optou-se pela abordagem qualitativa fenomenológica, visto que ela propõe o estudo dos fenômenos em seus cenários naturais, buscando compreender ou interpretar os significados que as pessoas thes conferem, olhando para o ser humano enquanto agentes cuja visão de mundo é o que realmente interessa (MOREIRA, 2002).

A pesquisa qualitativa aqui aplicada tem, como perspectiva, a análise hermenêutica das estruturas subjacentes aos desenhos. Os elementos selecionados, em uma pesquisa qualitativa, muitas vezes, seguem uma lógica diferente da pesquisa padronizada, ou seja, a pesquisa qualitativa obedece a lógicas distintas, podendo ocorrer por critérios, previamente estabelecidos, ou selecionados durante o processo com base nos dados obtidos (FLICK, 2009). No caso deste trabalho, os critérios de seleção dos elementos analisados foram definidos, previamente, de acordo com as categorias de análises.

Com essa compreensão, o enfoque qualitativo do trabalho é direcionado com base na experiência construída pelos sujeitos e no seu contato com o mundo. Mundo esse que quantitativa e qualitativamente é percebido cheio de significados, mundo que atribui às coisas percebidas novos sentidos e novos valores. A pesquisa qualitativa busca interpretar dados da realidade com base na perspectiva dos pesquisados. Considerando que ela representa dados de uma realidade específica, a pesquisa qualitativa se apresenta em um contexto histórico-social e temporal-espacial.

A primeira intervenção às turmas teve início com uma conversa sobre o descarte dos lixos eletrônicos (assunto abordado pela professora de ciências nas aulas anteriores), em seguida, os estudantes assistiram ao vídeo "História das Coisas" que teve, como objetivo, estimular os alunos a discutir o que percebem sobre o meio ambiente e seus problemas. Na sequência, os alunos foram convidados a fazer um desenho que retratasse como percebem o meio 
Percepção ambiental: um estudo numa escola pública municipal de Chapecó - Santa Catarina

ambiente. Para conclusão desta atividade, foram necessárias duas aulas, cada uma com, aproximadamente, quarenta minutos. $\bigcirc$ encontro foi finalizado com a socialização dos desenhos pelos estudantes.

A metodologia utilizada para analisar e apresentar os resultados ocorreu pela triangulação das informações contidas nos desenhos, nos textos produzidos pelos estudantes do $9^{\circ}$ ano e pela apresentação individual do desenho elaborado. Foi uma interpretação simples, porém criteriosa, identificando a presença de elementos que indicam como o sujeito percebe o meio ambiente.

Visando estabelecer uma aproximação dessa proposta com os desenhos efetivados pelos alunos, defiram-se as seguintes categorias como mediadora das análises dos resultados: Ser humano - categoria que propõe compreender a complexidade em si mesmo, nas ideias de unidade e de multiplicidade de não reduzir o todo às partes, nem as partes ao todo, com vistas ao entendimento das percepções ambientais representadas pelos sujeitos da pesquisa a partir das relações; Natureza/mundo - essas duas categorias juntas buscam analisar quais as significações atribuídas pelos alunos ao meio ambiente; Ser humano/Sociedade - propõe pensar a vida em sociedade, rompendo com dicotomias e paradigmas estabelecidos pelo pensamento cartesiano; Educação/auto-organização - pro-

90 põe uma discussão entre o sistema educacional e a sua auto-organização de tal forma que seja possível compreender como o meio ambiente é percebido pelos alunos do $9^{\circ}$ ano da Escola Municipal Victor Meirelles.

\section{Campo da pesquisa}

De acordo com os dados estatísticos' divulgados pelo IBGE (2015) e pelo Plano decenal dos direitos humanos da criança e do adolescente (CHAPECÓ, 2017), Chapecó - Santa Catarina - conta, atualmente, com quarenta escolas públicas municipais de Ensino Fundamental ${ }^{2}$, sendo 26 localizadas na área urbana e 14 localizadas na área rural. No ano de 2015, o município registrou 9.687 matrículas no Ensino Fundamental e, em 2016, esse número aumentou para 9.923 estudantes matriculados.

O bairro onde a escola está localizada integra, segundo o estudo ${ }^{3}$ realizado por Antunes (2015), um dos seis mais pobres de Chapecó. No mesmo ano, Dickmann (2015) constatou que 45,42\% das famílias recebiam recursos da Bolsa Família ${ }^{4}$ e uma parte considerável da população do bairro mantém, como sua renda principal, o trabalho com material reciclado. Uma das oportunidades de trabalho dentro do próprio bairro é na organização 
não-governamental Verde Vida, com sua ação interna chamada Programa Oficina Educativa ${ }^{5}$. Essa $O N G$ é uma associação com fins não econômicos que atua, desde 1994, no município de Chapecó, desenvolvendo importante trabalho social, de fortalecimento de vínculos e convivência educativa, além de atuar na área ambiental.

\section{Sujeitos da pesquisa}

Os participantes desta pesquisa foram os adolescentes do $9^{\circ}$ ano do Ensino Fundamental da EBM Víctor Meirelles. As turmas convidadas foram a 91 e 92, ambas do turno matutino. Na turma 91, havia 23 alunos sendo 16 meninas e 7 meninos, com 19 trabalhos concluídos. Já a turma 92 possuía 20 alunos, sendo 11 meninas e 9 meninos, com 20 trabalhos concluídos.

Como o objetivo era analisar as percepções que emergem do imaginário de estudantes numa Escola Municipal de Ensino Fundamental de Chapecó - Santa Catarina, um dos instrumentos para coleta de dados utilizado foi o desenho. Essa técnica, de acordo com Aguiar (2004), permite que os estudantes transcrevam informações acerca de suas experiências, construindo, desta forma, uma teia de possibilidades e significados, que, associados à sua produção textual, permitiu compreender a percepção de meio ambiente, manifestada pelos estudantes do $9^{\circ}$ ano. Isso se justifica pelo fato de, ao desenhar, os educandos expressam coisas diferentes da própria fala, é a oportunidade que eles têm de expressar o conhecimento acerca do mundo, uma espécie de projeção da sua própria existência e da dos outros, ou melhor, da maneira pela qual se sente existir e sente a existência dos outros.

\section{Discussões e resultados}

A técnica do desenho, como metodologia de pesquisa, revelou que o imaginário retrata uma consciência preocupada com o que está por vir Chaú (2000). Enquanto, no campo da imaginação, o objeto é posto na imagem como um objeto por inteiro, a percepção observa as coisas, as pessoas, as situações, mas nunca faz de uma só vez e por inteiro. Assim, vai articulando uma situação na outra, num processo contínuo, enriquecendo o conhecimento, percebendo e contemplando novos aspectos ao objeto observado.

Para Aguiar (2004), é necessário desvendar o fenômeno além da sua aparência, não se apegando aos fatos, mas ao significado fundamental 
Percepção ambiental: um estudo numa escola pública municipal de Chapecó - Santa Catarina

desses desenhos, sempre buscando uma compreensão do todo à parte e da parte para o todo. Afinal, o homem não tem existência independente do mundo. Na tentativa de estabelecer uma compreensão entre a percepção de meio ambiente e as relações estabelecidas em uma dimensão global é que se propõe proceder a uma análise dos desenhos selecionados, tendo, como suporte de análise, a base teórica utilizada nesta pesquisa. Vale dizer que "[...] o fenômeno é parte da relação que se estabelece entre os presentes. Ele não existe, mas é produto de interação, e se constrói em um processo mútuo de desvendamento e esclarecimento" (AGUIAR, 2004, p. 7).

De maneira análoga, o desenho cumpre com relevância seu papel. Surge antes da escrita e revela a maneira do homem, neste caso, o estudante, ver o mundo. Segundo Aguiar (2004, p. 10), "[...] sabemos que as chamadas pinturas rupestres, encontradas em paredes de antigas cavernas, traziam a representação simbólica da forma de viver do homem primitivo, seus conhecimentos, seus medos, suas atividades".

As decodificações desses desenhos em torno da percepção dos alunos dispõem de diversas possibilidades de interpretação. Tal como a ciência, não há como fornecer uma compreensão completa do fenômeno. Para Aguiar $92(2004$, p. 8), "[...] jamais se chega a um conhecimento definitivo, porque é do mundo da vida que se trata e a própria construção desse conhecimento [...] é elaborada conjuntamente".

As percepções de meio ambiente, retratadas pelos desenhos, apresentam ideias e compreensões através de ilustrações que permitem a captação de informações, sem que seja necessária uma intensa provocação e expressão verbal. Nesse tipo de coleta de dados, o pesquisador possibilita aos sujeitos pesquisados que representem por meio de desenhos fenômenos, situações e elementos que traduzem a sua percepção de meio ambiente. Mediante a elaboração dos desenhos, foi possível criar um ambiente de diálogo entre a pesquisadora e pesquisados, em que, posteriormente, com o elemento gráfico em mão, se estabeleceu uma conversa baseada em dados registrados nas imagens, possibilitando, assim, que a decodificação ficasse o mais fiel possível do que o sujeito pretendeu desenhar e a forma como este realmente percebe o meio ambiente.

Dos 43 estudantes convidados, apenas 39 estudantes concluíram a atividade. Desses, foram selecionados nove desenhos os quais foram 
decodificados na dissertação. Para este artigo, foram selecionados, apenas, quatro. Essa escolha se estabeleceu após uma análise criteriosa sobre as ilustrações e a explicação dos estudantes. Os instrumentos de coleta de dados utilizados no estudo foram: a elaboração de desenhos, um texto e análise de gravuras pelos alunos. Neste texto, serão apresentados, apenas, os resultados da análise dos desenhos.

Foram analisados 39 desenhos, 19 da turma 91, e 20 da turma 92. A análise dos desenhos teve início pela identificação dos elementos semelhantes presentes, sendo classificados de acordo com os elementos apresentados; assim, foi possível construir a Tabela 1 .

Tabela 1

Elementos que aparecem com maior e menor frequência nos desenhos

\begin{tabular}{|l|c|c|c|}
\hline \multicolumn{1}{|c|}{ Elementos } & Turma & Turma & $\begin{array}{c}\text { Quantidade } \\
\text { total }\end{array}$ \\
\hline Escola & 1 & 0 & 1 \\
\hline Solo (montanha, chão) & 0 & 1 & 1 \\
\hline Planeta (pequeno, grande, verde, polúido) & 1 & 2 & 3 \\
\hline Cidade (asfalto, prédios, carros, casas) & 2 & 3 & 5 \\
\hline Animais (pássaros, cachorros, peixes) & 4 & 2 & 6 \\
\hline Poluição (fumaça, poeira, tóxicos) & 6 & 5 & 11 \\
\hline Desmatamento (árvores cortadas, queimadas) & 9 & 4 & 13 \\
\hline $\begin{array}{l}\text { Humanos (homens, mulheres, crianças, sozinhos, } \\
\text { grupos) }\end{array}$ & 7 & 6 & 13 \\
\hline $\begin{array}{l}\text { Indústrias (fábricas, poluição, produção, grandes, } \\
\text { pequenas) }\end{array}$ & 11 & 2 & 13 \\
\hline $\begin{array}{l}\text { Reciclagem de lixo (associações, cooperativas, } \\
\text { classificação) }\end{array}$ & 10 & 3 & 13 \\
\hline Água (rios, lagos, chuva) & 3 & 11 & 14 \\
\hline Sol (pequeno e grande) & 7 & 7 & 14 \\
\hline Mata (árvores grandes e pequenas, sem frutos) & 13 & 15 & 28 \\
\hline
\end{tabular}

Fonte: Os autores.

Com base na Tabela 1, foi possível iniciar a classificação pelas categorias de análise.

Visando organizar as informações e facilitar a análise dos dados, esses elementos estão representados no Gráfico 1, sendo possível identificar, 
previamente, a diferença de elementos expressos pela turma 91, trazendo, para discussão, uma maior diversidade de elementos se comparado com a turma 92.

\section{Gráfico 1}

ELEMENTOS QUE APARECEM COM MAIOR E MENOR

FREQUENCIA NOS DESENHOS

= Quantidade total = Turma $92=$ Turma 91

Mata (árvoresgrandese pequenas, sem frutos)

Sol (pequeno e grande)

Água (rios, lagos, chuva)

Reciclagem de lixo

Industrias

Humanos

Desmatamento (árvorescortadas, queimadas)

Poluiçăo (fumaça, poeira, tóxicos)

Animais (pássaros, cachorros, peixes)

Cidade (asfalto, prédios, carros, casas)

Planeta (pequeno, grande, verde, poluido)

Solo (montanha, chão)

Escola

Fonte: Os autores.

Considerando as duas turmas e analisando os dados do Gráfico 1, o que chama a atenção é que, apenas, um desenho enfocou a escola, três desenhos trouxeram a representação do planeta, embora seja possível identificar, em 13 deles, a presença humana. Um mesmo número de desenhos apresenta características de desmatamento, pequenas e grandes indústrias, locais de reciclagem de lixo. Isso leva a perceber a semelhança com a realidade, vivenciada pelos estudantes.

\section{Análise dos desenhos e das citações dos alunos}

Ao final da dinâmica, foi solicitado aos alunos que cada um falasse sobre seu desenho. Neste texto, têm-se quatro desenhos que caracterizam os elementos apresentados, de modo geral, pelos alunos, associado à explicação do mesmo. 
É possível identificar, no desenho Al (Figura 1) da aluna A.C.G. que, em sua explanação, disse: "[...] algumas pessoas querem ajudar e outras querem destruir o mundo, primeiro o homem destrói a natureza para depois pensar em reconstruir". O relato da aluna corrobora o desenho, o qual é possível compreender que a relação estabelecida entre o ser humano e o mundo é mútua e, de fato, está ligada a uma dinâmica recíproca.

A estudante apresenta considerações importantes com relação ao ser humano e ao meio ambiente. Isso é reforçado no texto o qual suscita um possível debate em torno das ações do homem diante da natureza, do meio onde vive de modo característico sobre o entorno "[... ] no bairro não tem muitas árvores e tem muito lixo nas ruas, tem muitas pessoas que estragam o bairro, que não cuidam das coisas". Pela passagem, é possível estabelecer um diálogo amplo e constante nas mais variadas dimensões, sejam, sociais, econômicas, antropológicas, ambientais: é a relação Eu-Tu a que Freire (2002) se refere. Esse diálogo possibilita compreender as possíveis relações de poder veiculadas de maneira formal e sistemática na escola, nas relações socioambientais as quais são discutidas de maneira isolada e tratadas com certo reducionismo, ignorando o contexto dos sujeitos, fragmentação identificada no desenho A 1 .

\section{Desenho A1}

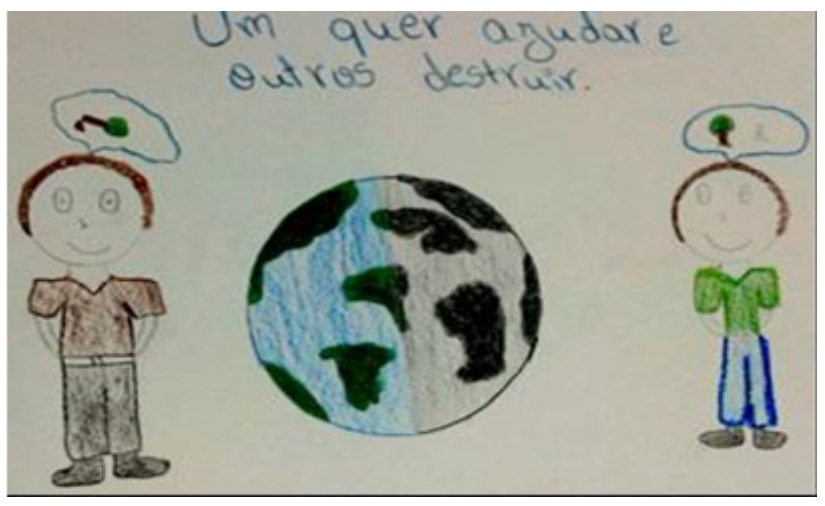

Autor: A.C.G.S. Turma 91

Fonte: Dinâmica da terceira fase da pesquisa.

As novas racionalidades dos saberes interdisciplinares impulsionam a interação do indivíduo com a natureza e a cultura, na dinâmica, ecológica, econômica, social, religiosa, enfim, entre a relação estabelecida pelos humanos em seu habitat, o planeta Terra (MORIN; KERN, 2003). 
É pertinente entender que isolar algo nessa rede complexa e chamá-lo de objeto seria um tanto arbitrário, mas é o que, comumente, se faz. Para Aguiar (2004), os jovens selecionam, ao desenhar, elementos e imagens que fazem parte do seu mundo, da sua vida, estabelecendo um diálogo entre o que a experiência de vida the proporciona e o que está simbolizado no desenho.

Essa experiência de que fala Aguiar é relatada em vários desenhos, elementos que remetem ao cotidiano dos adolescentes e que fazem parte do seu lócus existencial, como apresenta delicadamente o desenho C 1 (Figura 2).

Durante a socialização, M.J.N. compartilhou que o objetivo do seu desenho é "[...] mostrar a necessidade de dar um destino correto para os lixos". Também relata que "[...] muitos são possíveis reciclar". Pelo seu discurso, é possível estabelecer uma relação e uma aproximação do local, da experiência de vida com o desenho da aluna.

\section{Desenho $\mathrm{Cl}$}

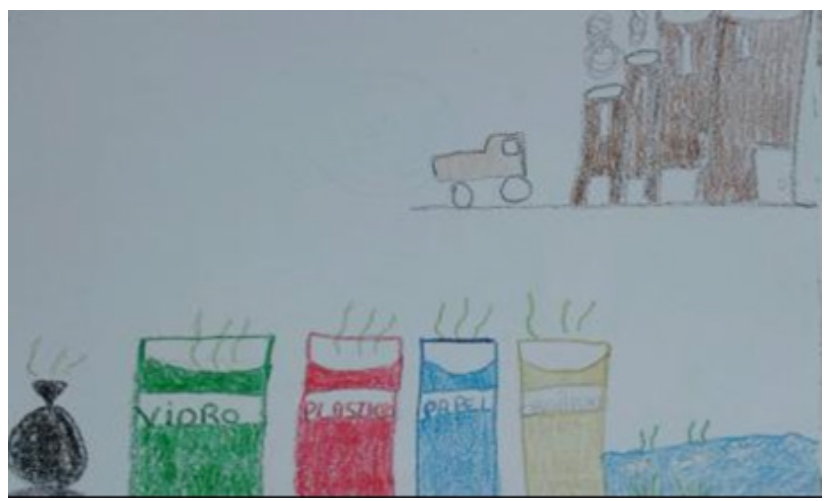

Autor: M.J.N. Turma 91

Fonte: Dinâmica da terceira fase da pesquisa.

A possibilidade de reconectar as informações tem a ver com a capacidade de os indivíduos ressignificarem o campo simbólico, o qual define e redefine a interpretação da natureza e do humano. Segundo a estudante M.J.N., promover uma educação ambiental crítica significa ampliar o olhar sobre questões socioambientais, não se resume somente em processos de reciclagens, coleta seletiva, ou sobre o cuidado com as árvores; urge um olhar para além das estruturas estabelecidas. 
A exemplo do desenho A2 e corroborando as ideias dos autores aqui estudados, é preciso olhar para todas as dimensões com o intuito de estabelecer um diálogo entre a percepção do estudante e o que apresenta o desenho. Conforme Carvalho (2008), o ser humano intervém na natureza através de suas relações, da sua concepção, dos desejos, da cobiça ou da sua visão de mundo.

\section{Desenho A2}

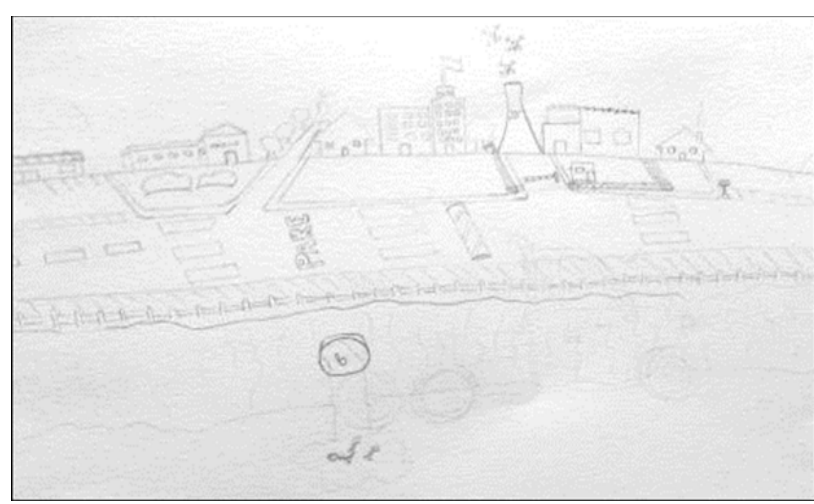

Autor: M.A.N. Turma 91

Fonte: Dinâmica da terceira fase da pesquisa.

O olhar sobre o desenho A2 (Figura 3) leva a diversas reflexões, entretanto toda visão possui certa dose de cegueira, já que há um movimento de indivisibilidade entre o sujeito que vê e a coisa percebida. Para Sato (2016), a fenomenologia de Merleau-Ponty considera que a visão não alcança uma visão plena do que aparece; portanto o visível tem sempre aspectos de invisibilidade; por esse motivo, é importante analisar o que disse o estudante M.A.N. sobre o seu desenho. Diz, M.A.N.: "[...] meu desenho representa a cidade, as indústrias que 'dão' empregos, desenvolvem e que fazem as coisas que nós compramos, mas estas indústrias jogam nos rios e no ar diversos polventes". Ele finaliza dizendo "temos que ajudar a preservar o planeta".

Vislumbrando os elementos que viabilizam a interpretação da paisagem demonstrada pelo estudante, chegou-se à seguinte reflexão: as dimensões sociais, econômicas e ambientais são retratadas pelo estudante de maneira bem característica no seu desenho, o contexto urbano o qual o sujeito está inserido é marcado pela degradação permanente do meio ambiente. Esse 
Percepção ambiental: um estudo numa escola pública municipal de Chapecó - Santa Catarina

enfraquecimento estrutural é relatado no texto, com a seguinte passagem "[...] ao redor da minha escola existe lixo, polvição, violência. $\bigcirc$ bairro precisa de ajuda em relação a isso, precisa de pessoas que lutem por essa causa" (M.A.N.).

A relação de preocupação com o outro ${ }^{6}$ é relatada pela estudante na passagem "há muitas casas de pessoas humildes, um bairro bem agitado", características já representadas no desenho A2 e que se fortalece à medida que se vai analisando e decodificando as outras imagens.

Perceber as intensas alterações que o planeta Terra vive, em paralelo com a evolução do modelo de vida humana, não diz respeito apenas a uma das dimensões da tríade indivíduo-sociedade-espécie apresentada por Morin (201 1), isso porque configura o seguinte entrelaçar aqui demonstrado pelos sujeitos pesquisados: a sociedade vive para o indivíduo, o qual vive para a sociedade, a sociedade e o indivíduo vivem para a espécie, a qual vive para o indivíduo e para a sociedade.

A despeito dessa dinâmica, o aluno A.N. (turma 92) relata que a proposta do desenho C2 é demonstrar "[...] um planeta como meio ambiente, de onde vêm às coisas que vão para as fábricas, que processam e mandam para as distribuidoras, das distribuidoras às lojas e daí para nossas casas".

\section{Desenho C2}

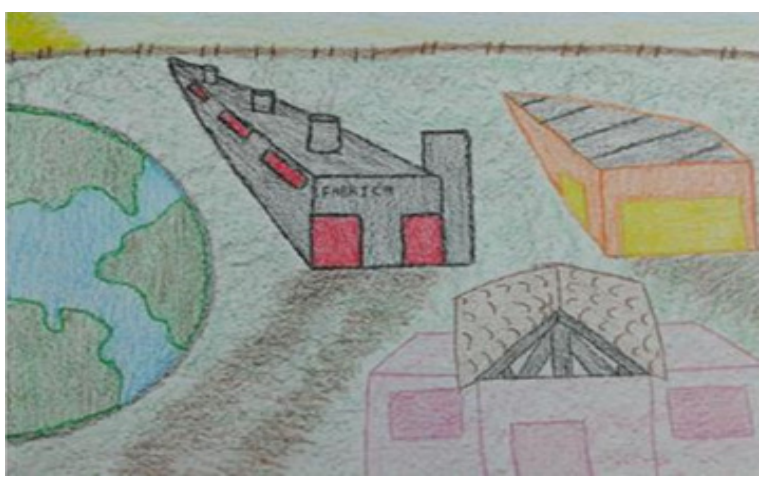

Autor: A.N. Turma 92

Fonte: Dinâmica da terceira fase da pesquisa

Observando, atentamente, o desenho, é possivel identificar o ciclo mencionado pelo aluno. $O$ planeta representa o meio ambiente que, em sua 
visão, está a serviço do homem, pois fornece os materiais necessários para as indústrias. Na sequência, tem-se a fábrica (como) um sinônimo de crescimento e desenvolvimento econômico, mas também sinônimo e símbolo de preocupação quanto os maus tratos com o meio. $O$ estudante compreende o papel da distribuidora (identificar) nessa dinâmica, de tal modo que próxima dela está o que pode ser considerado pela transcrição do aluno como a casa, ponto-alvo da indústria.

Pelo desenho C2, é possível, claramente, vislumbrar o pensamento cartesiano, operando na relação sociedade e ser humano. Isso fica claro com a divisão dos elementos no desenho e se caracterizam nas disposições das estruturas, as quais instrumentalizam o mundo de forma homogênea, autoritária e excludente, unicamente em prol da rentabilidade do mercado.

Tais disposições instigam a pensar as relações estabelecidas e, nessa ótica, as representações visuais têm a ver com a constituição das subjetividades construídas singularmente, porém alimentadas na pluralidade. Para Petraglia (2008), é viver entre o prazer e a dor da aventura, entre o real e o imaginário, na simultaneidade do uno e do múltiplo.

\section{Conclusão e considerações indicativas}

Considerando a relevância do tema meio ambiente nos dias atuais, é importante considerar que trabalhar a educação ambiental, desde a infância, como sugere Morin (2003), é algo necessário para a constituição de um sujeito, capaz de compreender a dinâmica relacional a qual o homem está inserido. Tudo que se pode saber do mundo se resume a fenômenos, a objetos ou ideais que existem na mente, situações oferecidas pelas percepções, pela imaginação, pela memória e pela linguagem que formam redes de significações em nosso mundo. Convém receber e atribuir sentidos aos fenômenos com o propósito de descobrir e compreender o funcionamento das estruturas essenciais que os constituem.

Assim, com o propósito de responder à pergunta: quais percepções de meio ambiente emergem do imaginário de estudantes numa Escola Municipal de Ensino Fundamental de Chapecó, Santa Catarina?, o trabalho tinha como objetivo analisar as percepções de meio ambiente que emergem do imaginário de estudantes numa Escola Municipal de Ensino Fundamental de Chapecó, Santa Catarina. 
Percepção ambiental: um estudo numa escola pública municipal de Chapecó - Santa Catarina

Nesse sentido, estudar as percepções é buscar compreender que há uma infinidade de pensamentos que influenciam e podem ser abordados pelas mais diversas perspectivas. Compreender essas influências não significa esgotá-las em sua essência, mas estabelecer as relações necessárias para que, em outros momentos, essas problemáticas possam ser discutidas.

Este estudo demonstrou a importância e a necessidade de pensar a ciência unificada ao ser humano, o que, em sociedade, implicaria o fim das disciplinas especializadas, das separações fortalecidas no meio educacional. É preciso religar saberes, romper com o processo que, no presente, sob a influência do pensamento cartesiano, formam especialistas e que, por motivos práticos, estabelecem modelos de sistemas, segmentam e não consideram o ser humano como um todo ou como parte integrante da natureza. É essa experiência que Larrosa Bondía (2002) define como algo que me toca; isso porque a experiência não é descoberta, mas inventada, se faz sobre algo que se descobre dialeticamente.

Entende-se que os desenhos dos alunos sobre o meio ambiente podem representar o que eles conhecem e sabem sobre o tema. Portanto, o enfoque de elementos naturais nos desenhos sem a expressiva presença humana pode 100 indicar a necessidade de inserir a dimensão social nas questões sobre o meio ambiente.

Ao finalizar a análise dos desenhos, conclui-se que a turma 91 apresentou uma maior quantidade de elementos os quais são passiveis de problematização, possibilitando uma compreensão ampliada do que se define como percepção de meio ambiente. Já a turma 92 apresentou uma característica ecológica de meio ambiente sem problematizar ou relacionar com o meio.

Seria interessante se o diálogo, entre o ser humano, a natureza, o mundo e a sociedade, pelo processo educativo, considerasse o sujeito em sua complexidade, na sua inteireza, para, através de suas vivências, e dos sentidos, as percepções pudessem compreender e tratar as questões de meio ambiente com totalidade e profundidade.

Os resultados permitem concluir, ainda, que, enquanto a turma 91 apresentou uma leitura complexa, ampla no que se refere à problematização e à compreensão de ser humano interligado ao todo, a grande rede da vida, a turma 92 apresentou uma percepção fragmentada, em que a relação ser 
humano, meio ambiente e mundo é construída isoladamente, sem o devido tratamento e a necessária problematização.

A pesquisa demonstrou que, no âmbito educacional, a fragmentação disciplinar existente produz equívocos e distorções na postura e na forma de compreensão do meio ambiente. A análise das duas turmas foi extremamente importante para confirmar à pesquisa que o contexto social, econômico, cultural, em especial, ambiental, do indivíduo, tem significativa influência na formação perceptiva dos estudantes.

Com base no desenvolvimento da pesquisa, justifica-se trazer considerações indicativas para futuras pesquisas com o propósito de compreender a complexidade, com vistas a percepções ambientais, representadas pelos sujeitos da pesquisa:

- $\quad$ Compreender o lócus como algo que faz parte de um todo maior é entender que o equilíbrio e o desequilíbrio, a ordem e a desordem, a incerteza e a certeza fazem parte de um movimento que tem influência do e no homem. É um sistema que se regenera, cria, se reproduz, um projeto inacabado e sempre estará se reconstruindo, portanto, não é possível negá-lo. Contemplar o sujeito, em sua complexidade, enfatiza o aprendizado através de suas experiências e vivências, por meio dos sentidos e das percepções do próprio corpo. Esse comportamento é capaz de ampliar nossa relação com o mundo junto à pluralidade das interpretações.

- $\quad$ Propor, no âmbito educacional, um olhar com vistas à complexidade é estabelecer um elo entre o que se apreende e o que se vive, religando o conhecimento com o contexto de vida. Assim, promove-se um novo educar, que demonstre aos estudantes e educadores que não existe ciência pura, nem verdades absolutas no campo do conhecimento. Portanto, o pensamento complexo navega em um mar de incertezas e deve detectar a dialógica, certeza-incerteza, necessárias para compreensão do homem como indivíduos-sujeitos que emergem na realidade fenomenal.

- $\quad$ imaginário, a percepção e os desenhos permitem aos jovens integrar diversos aspectos da realidade, muitas vezes conflitantes, porém complementares e que podem ser tensionados pelas discussões educacionais, de forma criativa e produtiva. Afinal, trata-se de um momento dinâmico, um processo do qual não se tem certeza do resultado final. 
Percepção ambiental: um estudo numa escola pública municipal de Chapecó - Santa Catarina

- Meio ambiente como uma proposta de criar condições de pertencimento ao universo, em toda a sua extensão, na forma como habitamos mutuamente o mundo. $\bigcirc$ que se defende, como percepção de meio ambiente, é a necessidade de uma educação conectada com os sentidos, com as concepções individuais e coletivas vivenciadas, possibilitando, assim, a transformação de comportamentos, abrindo caminho para um saber compromissado, comprometido e articulado em torno de um projeto claramente exposto que é a vida.

- Superar as dicotomias existentes nas relações [me] parece fundamental para compreender a interação do homem com as condições sociais, econômicas, ambientais, as quais ele é submetido. Superação que perpassa as mais variadas estruturas, rompendo com o pensamento cartesiano e trazendo à luz problemas mascarados pela sociedade.

- $\quad$ Compreender que o sujeito sofre influência na concepção da sua percepção é olhar para as relações como uma teia da qual o indivíduo está conectado. É compreender que as ações interferem sobre o todo e que as mudanças ocorridas ou não ocorridas têm reflexos positivos ou negativos em qualquer âmbito dessa teia. Daí, a necessidade de pensar a religação dos saberes, de mudar paradigmas.

- Mudanças que demandam tempo, e na educação não é diferente, requerem muita reflexão; afinal, todo sistema educacional está pautado em paradigmas conservadores, os quais não são fáceis abandoná-los. Pensar a escola pautada pelo paradigma da complexidade é estar ciente da necessidade de uma prática pedagógica que priorize a formação de um homem responsável pela sua vida e a de seus semelhantes, ampliando, deste modo, sua capacidade perceptiva em volta do todo.

\section{Notas}

1 Fonte: Ministério da Educação, Instituto Nacional de Estudos e Pesquisas Educacionais (Inep), Censo Educacional 2015

2 O recorte apresenta dados do Ensino Fundamental pelo fato de a pesquisa ser desenvolvida com os alunos do $9^{\circ}$ ano. Porém, o Plano decenal dos direitos humanos da criança e do adolescente (CHAPECÓ, 2017) apresenta dados correspondente ao que tange à educação de Chapecó.

3 Antunes (2015), com o tema Lugares, redes e socialidades: estudo etnográfico nas periferias de Chapecó (SC), apresenta resultados da etnografia que se concentrou na região Leste do município, principalmente nos bairros São Pedro e Bom Pastor, caracterizando esses lugares a partir das concepções e experiências de seus moradores. 
4 Em Chapecó, há 3.570 famílias beneficiárias do Bolsa Família, 4,93\% da população total do município, e inclui 139 famílias que, sem o programa, estariam em condição de extrema pobreza. Em março de 2017, foram transferidos $R$ \$ 441.041,00 às famílias do Programa e o benefício médio repassado foi de R\$123,54 por família. Disponível em: www.mds.gov.br/ bolsafamilia. Acesso em: 15 abr. 2017.

5 Informações coletadas junto ao site do Verde Vida. Disponível em: hitp://verdevida.org.br/ quem_somos.php. Acesso em: 15 abr. 2017.

6 A compreensão de outro neste fragmento do texto está ligada diretamente ao outro, no sentido de ser humano, ser vivo e não-vivo, de ambiente, de planeta, os quais interagem em uma dinâmica inter-relacional permanente. Uma relação de alteridade existencial, de cuidado necessário às práticas diárias individuais e coletivas, que corresponde ao que está fora e dentro de nós ao mesmo tempo.

\section{Referências}

AGUIAR, Eloísa. Desenho livre infantil: leituras fenomenológicas. Rio de Janeiro: E-papers, 2004.

ANTUNES, Camila Sissa. Lugares, redes e socialidades: estudo etnográfico nas periferias de Chapecó (SC). 2015. 370f. Tese (Doutorado em Antropologia Social) - Programa de Pós-Graduação em Antropologia Social da Universidade Federal de Santa Catarina, Florianópolis, 2015.

CAPRA, Fritjof. A teia da vida: uma nova compreensão científica dos sistemas vivos. São Paulo: Cultrix, 1996.

CARVALHO, Isabel Cristina de Moura. Educação ambiental: a formação do sujeito ecológico. 3. ed. São Paulo: Cortez, 2008.

CHAPECÓ. Prefeitura Municipal. Banco de dados: informações estatísticas do município de Chapecó. Chapecó, 2014. Disponível em: http://www.chapeco.sc.gov.br/chapeco/ chapeco-dados.html. Acesso em: 9 mar. 2016.

Plano decenal dos direitos humanos da criança e do adolescente. Chapecó: Conselho Municipal dos Direitos da Criança e do Adolescente, 2017.

CHAUÍ, Marilena. Convite à filosofia. São Paulo: Ática, 2000.

DICKMANN, Ivo. A formação de educadores ambientais: contribuições de Paulo Freire. 2015. $315 f$. Tese (Doutorado em Educação) - Programa de Pós-Graduação em Educação, Universidade Federal do Paraná, Curitiba, 2015.

FLICK, Uwe. Desenho da pesquisa qualitativa. Porto Alegre: Artmed, 2009. 
Percepção ambiental: um estudo numa escola pública municipal de Chapecó - Santa Catarina

FREIRE, Paulo. Pedagogia do oprimido. 33. ed. Rio de Janeiro: Paz e Terra, 2002.

LARROSA BONDÍA, Jorge. Notas sobre a experiência e o saber de experiência. Revista Brasileira de Educação, Campinas, n. 19, p. 20-28, jan./abr. 2002.

MERLEAU-PONTY, Maurice. Fenomenologia da percepção. 2. ed. São Paulo: Martins Fontes, 1999.

MOREIRA, Daniel Augusto. O método fenomenológico na pesquisa. São Paulo: Pioneira Thomson, 2002.

MORIN, Edgar. A cabeça bem feita: repensar a reforma do pensamento. 4. ed. Rio de Janeiro: Bertrand Brasil, 2003.

2011.

Os sete saberes necessários à educação do futuro. 2. ed. São Paulo: Cortez,

; KERN, Anne Brigitte. Terra-pátria. Porto Alegre: Sulina, 2003.

PETRAGLIA, Izabel. Complexidade em tempos incertos. Porto, Portugal, 2008.

SATO, Michèle. Ecofenomenologia: uma janela ao mundo. Revista Eletrônica do Mestrado em Educação Ambiental, Rio Grande, jul. 2016.

Profa. Me. Simone Ruppenthal Unidade Central de Educação Faem Faculdades Palavração - Grupo de Estudos, Pesquisa e Documentação em Educação Ambiental Freiriana E-mail | ruppenthal@unochapeco.edu.br

Prof. Dr. Ivo Dickmann Universidade Comunitária da Região de Chapecó | Unochapecó Chapecó | Santa Catarina Programa de Pós-Graduação em Educação | Mestrado Palavração - Grupo de Estudos, Pesquisa e Documentação em Educação Ambiental Freiriana E-mail | educador.ivo@unochapeco.edu.br 
Prof. Dr. Ireno Antonio Berticelli Universidade Comunitária da Região de Chapecó | Unochapecó Chapecó | Santa Catarina Programa de Pós-Graduação em Educação | Mestrado

Grupo de Pesquisa Formação de Professores, Produção do Conhecimento e Processos

Pedagógicos

E-mail | ibertice@gmail.com

Recebido 3 abr. 2018 Aceito 23 abr. 2018 